\title{
Project risk management in Iranian small construction firms
}

\author{
Nima Amani ${ }^{*}$ and Keyvan Safarzadeh
}

\author{
* Correspondence: nimaamani@ \\ iauc.ac.ir \\ Department of Civil Engineering, \\ Chalous Branch, Islamic Azad \\ University, P.O. Box 397/46615, \\ Chalus, Iran
}

\begin{abstract}
The objective of this study is to evaluate RM in small projects in Iran using identification of status, barriers, and the impact of RM on project performance. In this study, theoretical foundations and research literature were first developed through library, and then a questionnaire about these variables was designed and distributed among a number of experts in the active construction companies. Data were collected from 40 projects submitted by 25 experts from 5 executive companies. According to the studies, 10 barriers are identified as major obstacles to RM implementation in such projects, prioritized as follows: (1) lack of potential benefits, (2) not economical, (3) lack of time, (4) lack of budget, (5) lack of knowledge, (6) lack of government legislation, (7) lack of manpower, (8) low profit margin, (9) complexity of analytical tools, and (10) competition among SMCs. The findings of this research can provide an in-depth understanding of RM in small projects in Iran and make benefits of RM convincing to the participants of small projects.

Keywords: Risk management, Small projects, Implementation, Barriers, Impact, Project performance
\end{abstract}

\section{Introduction}

The annual budget raise of national construction projects is a reason for the key role of country's construction industry. Based on various studies, small projects make up a majority of projects completed in the industrial sector, planning of these projects varies greatly across the industry [8]. On the other hand, according to the current economic situation of the country (Iran) and its influence on all industries, including the construction and, subsequently, the tendency of major employers and contractors to divide large scale and complex projects into smaller and simpler ones and perform them through subcontractors, therefore, the number of small construction projects has been increasing in recent years. So, it is important to be sure about the success of these types of projects. Construction projects can be classified in different sizes for different objectives. However, a common but impalpable indicator exists in all projects which are called project risk. As the project risk increases, the management and project control gets difficult [22]. Many failures occur in the project due to the risk and instability in the environment and within the project structure. Nevertheless, due to the risk

(c) The Author(s). 2021 Open Access This article is licensed under a Creative Commons Attribution 4.0 International License, which permits use, sharing, adaptation, distribution and reproduction in any medium or format, as long as you give appropriate credit to the original author(s) and the source, provide a link to the Creative Commons licence, and indicate if changes were made. The images or other third party material in this article are included in the article's Creative Commons licence, unless indicated otherwise in a credit line to the material. If material is not included in the article's Creative Commons licence and your intended use is not permitted by statutory regulation or exceeds the permitted use, you will need to obtain permission directly from the copyright holder. To view a copy of this licence, visit http://creativecommons.org/licenses/by/4.0/. The Creative Commons Public Domain Dedication waiver (http://creativecommons.org/publicdomain/zero/1.0/) applies to the data made available in this article, unless otherwise stated in a credit line to the data. 
intangibility, no comprehensive and complete definition has yet been presented. Meanwhile, no comprehensive quantitative relationship that can measure the project risk and represent its entire aspects has been provided [18]. According to the Project Management Institute [23], project risk is an uncertain event that, if it occurs, impacts at least one project objective (e.g., quality, cost, time, etc.), and project RM intends to increase the probability and impact of positive events and decrease the probability and impact of negative ones. Therefore, project RM implementation would improve project performance through assuring the achievement of project objectives and pursuing opportunities to increase positive impacts on goals. In addition, project RM has been considered as one of the ten project management knowledge areas (PMI, 2017) and enables stakeholders to understand the risk impacts on project performance [1, 11]. Although the result of these scientific efforts has led to the design and development of models and tools to identify and manage the risks in this industry, the construction projects especially in Iran are still far from the expected and satisfying performance level [19].

Many researches have been carried out about RM in different types of projects (construction, services, etc.), but less researches have been conducted to explore this matter in small construction projects. Since, the structure, situation, and characteristics of small construction projects are very different from large and medium projects, so, considering the small construction projects is important. Therefore, it is necessary to conduct studies particularly about the impact of RM implementation on such projects, and the current condition of RM implementation, implementation challenges, and its impact on RM in small construction projects should be evaluated. Table 1 shows previous major studies (last 5 years) about RM in construction industry, small projects, and implementation barriers.

The objectives of this study are (1) to investigate the current status of RM implementation in small construction projects in Iran, (2) to identify the barriers to RM implementation, (3) to capture the perceived importance of $R M$ in improving project performance, and (4) to explore the perceived impact of RM on project performance.

Table 1 Summary of pervious major studies (last 5 years) on RM in the construction industry, small projects, and implementation barriers

\begin{tabular}{|c|c|}
\hline Ref. & Research Method \\
\hline Collins, Parrish and Gibson [8] & $\begin{array}{l}\text { A questionnaire survey of } 314 \text { experiences based on data collected } \\
\text { from } 60 \text { projects. }\end{array}$ \\
\hline $\begin{array}{l}\text { Hamdvand, Eghbali, Kobraieh Abkenar, } \\
\text { and Moghamipour [14] }\end{array}$ & $\begin{array}{l}\text { A questionnaire survey based on data collected from local } \\
\text { construction contractors of various dimensions in Iran. }\end{array}$ \\
\hline Hwang, Zhao, and Toh [16] & $\begin{array}{l}\text { A questionnaire survey of } 15 \text { consultants and } 19 \text { contractors in } \\
\text { Singapore based on data collected from } 668 \text { projects. }\end{array}$ \\
\hline $\begin{array}{l}\text { Serpella, Ferrada, Howard, and Rubio } \\
\text { [27] }\end{array}$ & An internet questionnaire of management of companies in Chile. \\
\hline Choudhry and Iqbal [4] & $\begin{array}{l}\text { A questionnaire survey of } 80 \text { key participants in Pakistan based on } \\
\text { data collected from } 4 \text { main centers. }\end{array}$ \\
\hline Chileshe and Kikwasi [5] & $\begin{array}{l}\text { A questionnaire survey of construction professionals in Tanzania } \\
\text { based on data collected from } 27 \text { consultants, } 24 \text { contractors and } 16 \\
\text { client organizations. }\end{array}$ \\
\hline Chileshe and Yirenkyi-Fianko [6] & $\begin{array}{l}\text { A survey of randomly selected samples yielded responses from } 34 \\
\text { contractors, } 46 \text { consultants, and } 23 \text { clients or owners (private and } \\
\text { public) in Ghana. }\end{array}$ \\
\hline
\end{tabular}




\section{Small construction projects}

An identical and agreed definition of small projects has not been presented in the research literature, yet. However, some features and characteristics of these projects have been identified in previous studies.

The Construction Industry Institute [7] revealed that small projects would have less staff and formal controls, higher project contingency, and more standardized process and use of checklists.

In addition, Griffith and Headley [13] believed that small projects were likely to have short duration and higher uncertainty, limited of formal documentation, and considered the disproportion between management investment and project cost as the main problem in these types of projects.

Also, Dunston and Reed [9] stated that small projects were those with the following characteristics: (1) repetitive and distinctive activities, (2) simple construction and execution processes, (3) maintenance projects, (4) reconstruction, (5) model changing or upgrade, and (6) total project expenses less than 1 million USD\$.

Furthermore, Liang [18] believed that small projects should have at least one of the following characteristics: (1) project costs between 0.1 and 5 million USD\$, (2) project duration of 14 months or less, (3) less than $100,000 \mathrm{~h} /$ project work time, and (4) no need for full-time access to project resources or a substantial portion of organization's resources. According to Liang [18], small construction projects are limited to projects between 0.1 and 5 million USD\$ and less than 14 months of work time.

According to the contents and definitions mentioned in the research literature, features of small construction projects can be summarized as follows: (1) standard execution duration less than 14 months, (2) project cost between 0.1 and 1 million USD\$, (3) 10 to 100 full-time manpower to perform the project, and (4) more informal and less documentation and control compared to large projects.

\section{RM in small construction projects}

Small projects should be managed very carefully, so the project does not exceed from the predicted cost and time. Despite of high importance of RM in small projects, this matter is often neglected in projects due to being costly and much needed information [21].

Small and medium construction companies (SMCs) that usually carry out small projects do not have much tendency to manage the risk in these projects and also do not have the necessary knowledge and information about these kinds of projects $[15,26]$;). Moreover, intense competition forces SMCs to price their bids so low that they cannot have excess budget for contingency [26]. But the studies indicate that RM can improve predicted costs and decision-making [20] and also can help the project to be completed at predetermined time and cost [2] as well as reduce the risk damages [17].

Risk and its management have high importance due to their direct relation with working agents, because mismanagement can cause performance reduction and even failure of the project. There are no exceptions for construction projects because many people are involved including the contractor and employer consultant. Studies show that technical and executive factors have no significant effect on the small projects performance, unlike economic and financial factors [24, 25]. The risks of small 
construction projects can be classified into nine phases (phase 0: demonstrate need, phase 1: understanding the need, phase 2: feasibility study, phase 3: study the real feasibility and financial validity of the project, phase 4: general concept design, phase 5: complete concept design, phase 6: coordinated design, preparation and full funding, phase 7: construction information, phase 8: construction, phase 9: operation and maintenance) after investigating the research results. On the other hand, the evaluation results and ranking the factors affecting risks in small construction projects show that the employer, with $42.3 \%$, has the highest influence on risk occurrence in small construction projects based on the process-driven RM and then the consultant and contractor affect the risk with $36.3 \%$ and $21.5 \%$, respectively [10].

Hwang et al. [16] investigated the RM of small construction projects in Singapore. They presented a definition of SMCs and determined the characteristics of these projects in their paper. Then, the risks involved in these projects performance have been identified, and the impact of each risk on the project has been determined. Ultimately, strategies to manage risk in these projects were provided. They implemented their model on a case study of small projects in Singapore.

Some gaps and vacuities can be found in the research literature through a subject literature review, and most of them are as follows: (1) lack of RM consideration in small projects, (2) general RM discussion or its consideration for major construction projects, (3) lack of providing a comprehensive and complete definition for small construction projects, and (4) research pause in the risk identification phase and lack of RM analysis in the projects.

In this study, we try to provide a comprehensive definition of small construction projects in Iran, in addition to addressing the issue of risk in such projects and analyzing the reasons for lacking of risk management in these projects and providing solutions to these obstacles, we offer solutions.

\section{Methods}

In this study, theoretical foundations and research literature were first developed through library resources (books and articles about research variables); then, in order to perform a field study in accordance with the research literature, a questionnaire about these variables was designed and distributed among a number of experts in the active construction companies around the country (consultant and contractor), ranked 3, 4, and 5 from the Management and Planning Organization of Iran in the building field and holding projects in different regions of the country during past 5 years (having a head office in Tehran) selected by cluster sampling.

A condition of at least 5 years of work experience was considered for selecting the experts participating in this study. It should be noted that the reason of selecting the companies ranked 3, 4, and 5 is that companies rated 2 and 1 are usually not involved in small projects due to their ability to participate in higher tender offers and they have less tendency to carry out small construction projects. Finally, after collecting questionnaires, the related data were analyzed using SPSS and Expert Choice software packages.

Notice: In the first distribution, questionnaires were sent to 35 companies with the above conditions; but after more than 2 months and despite of continuous pursuance, only 2 questionnaires were answered incompletely which were not sufficient and acceptable to achieve the research objectives. The reasons of low responses can be 
attributed to the following: (1) confidential and sensitive information that companies do not tend to reveal, (2) insufficient familiarity with the subject, and (3) relationship disconnection between university and industry and etc. Therefore, in the second distribution, 5 active contracting companies in Tehran were randomly selected, and 25 individuals were selected as experts in this research out of those 5 companies.

In order to determine the reliability, the Cronbach's alpha method was used to verify validity, content validity (according to the strong background of models and variables consideration in the main models for the questionnaires preparation), and exponential validity (investigated by the professors). The distributed questionnaires consist of 5 parts including an introduction and four main sections, they are as follows:

A) Introduction: includes important researches defining small construction projects, research objectives description, and questions about small construction projects definition from experts perspective.

B) First section: includes basic information of experts and related companies and the projects description carried out in last 5 years.

C) Second section: includes the current status consideration of RM execution and implementation in the relevant company (active projects of last 5 years-from April 2012 onwards - where RM has been formally implemented and executed).

D) Third section: includes RM barriers in small construction projects and the importance determination of these factors and barriers through paired comparisons.

E) Fourth section: includes impact investigation and also the importance of RM on main factors in small construction projects and the extent of it.

As mentioned before, in the first step, it is necessary to present a definition of small construction projects. So, experts were asked to present their definition of small construction projects in the "Introduction" section. After gathering the expert' opinions and concluding their comments, the following definition of small construction projects was presented finally.

Small construction projects are construction once (1) their standard time duration is less than 14 months; (2) their expenses is between 0.1 and 1 million USD\$, the equivalent of 4 to 40 billion Iranian Rials; (3) they have manpower of 10 to 100 full-time personnel for executing projects; and (4) they have less and more informal control and documentation compared to large projects.

After providing a definition for small construction projects in the "Introduction" section, the information about experts, companies, and projects carried out in past 5 years was gathered in the first section. Table 2 shows the demographic characteristics of chosen experts from the collected questionnaires.

Table 3 shows the profile of the 5 companies studied in this research.

Table 4 is regulated based on the projects differentiation carried out by mentioned companies in the last 5 years according to their type, nature, cost, and time duration.

Out of 40 reviewed projects, $52.5 \%$ were private that according to the company's rating, it may be due to the fact that the contractor selection indicator for public projects 
Table 2 The demographic characteristics of chosen experts

\begin{tabular}{|c|c|c|c|c|}
\hline Characteristics & & & $N$ & $\%$ \\
\hline \multirow[t]{5}{*}{ Experts $(N=25)$} & Degree & B.S. & 15 & $\overline{60}$ \\
\hline & & M.Sc. & 9 & 36 \\
\hline & & Ph.D. & 1 & 4 \\
\hline & Gender & Male & 23 & 92 \\
\hline & & Female & 2 & 8 \\
\hline \multirow[t]{4}{*}{ Years of experience } & & $<10$ & 10 & 40 \\
\hline & & $10-15$ & 7 & 28 \\
\hline & & $15-20$ & 6 & 24 \\
\hline & & $>20$ & 2 & 8 \\
\hline
\end{tabular}

is more accurate than private projects. Therefore, contractors with this rank can win the private project tender offers more easily.

Also, $47.5 \%$ of these projects are reconstruction activities in nature which indicates that a significant part of the construction market in developing countries contains these types of projects and mostly done by companies with this ratings.

In addition, $80 \%$ of all projects carried out by chosen companies worth less than 40 billion rials and $62.5 \%$ of them have been executed in less than 14 months. It shows that most of the studied projects were small ones.

\section{Results and discussion}

\section{Status of risk management implementation \\ Company level}

In this step, the current situation of RM execution was investigated at company level. Thus, each five company's representatives were asked to convey their projects characteristics during last 5 years (April 2012 onwards) in which RM has been formally implemented and executed.

Table 5 is regulated based on the projects' differentiation formally implemented and executed according to their type, nature, cost, and time duration.

Thus, the RM implementation index (RMII), which describes the extent of RM implementation in a company, can be calculated using the following formula, and the results are shown in Table 6:

RMII $=$ no. of projects with RM implementation/total no. of projects in a company $\times$ $100 \%$

In Table 6, the RMII total average is $33.32 \%$, which indicates that the RM implementation is low in companies that are mostly active in small construction projects. The

Table 3 Information of 5 companies studied here

\begin{tabular}{llllll}
\hline Company\# & Type & Activity & Rating & History & No. of projects \\
\hline 1 & Private & Contractor & 4 & $<10$ years & 8 \\
2 & Private & Contractor & 4 & $<10$ years & 9 \\
3 & Private & Contractor/consultant & 3 & $10-20$ years & 6 \\
4 & Private & Contractor/consultant & 5 & $10-20$ years & 8 \\
5 & Private & Contractor & 4 & $<10$ years & 9 \\
\hline
\end{tabular}


Table 4 The project details carried out by each company separately

\begin{tabular}{|c|c|c|c|c|}
\hline \multicolumn{3}{|l|}{ Characteristics } & \multirow{2}{*}{$\begin{array}{l}\boldsymbol{N} \\
19\end{array}$} & \multirow{2}{*}{$\frac{\%}{47.5}$} \\
\hline Projects $(N=40)$ & Type & Public & & \\
\hline & & Private & 21 & 52.5 \\
\hline & Nature & New con. & 21 & 52.5 \\
\hline & & RMAA & 19 & 47.5 \\
\hline & Cost (Rials) & $<4$ billion & 10 & 25 \\
\hline & & 4-40 billion & 22 & 55 \\
\hline & & $>40$ billion & 8 & 20 \\
\hline & Duration & $<6$ months & 11 & 27.5 \\
\hline & & 6-14 months & 14 & 35 \\
\hline & & $>14$ months & 15 & 37.5 \\
\hline
\end{tabular}

results also indicate that high-ranked companies are more willing to implement and execute RM in their projects; they are equipped with experience, resources, advanced technology, experts, and professional staff and more tended toward risk management.

\section{Project level}

Table 7 shows the number and proportion of projects with RM implementation.

The summarized results in Table 7 indicate that against the initial expectation, RM implementation in private projects (33.3\%) was higher than public projects (31.5\%) probably due to fact that private section has more emphasis on general quality and considers RM as one of the determining indicators for contractor's score during the evaluation of a tender offer and its price.

Also, RMAA works has more uncertainty and risk compared to new construction projects, and RM implementation will help the project team to better prepare for potential risks ([3]- [12]), but according to the results (26.3\%), it is obvious this matter has not been considered seriously in our country and gets less attention. On the other hand, the matter of RM implementation more than 4 to 40 billion Rials (36.4\%) and under 4 billion Rials (10\%) projects which is completely consistent with the initial hypothesis of this study stating that low profitability of small projects leads to inadequate and even zero budget allocation to planning, implementation, and execution of RM. In

Table 5 Projects characteristics having RM system by each companies

\begin{tabular}{|c|c|c|c|c|}
\hline \multicolumn{3}{|l|}{ Characteristics } & \multirow{2}{*}{$\begin{array}{l}\boldsymbol{N} \\
6\end{array}$} & \multirow{2}{*}{$\begin{array}{l}\% \\
46\end{array}$} \\
\hline Projects $(N=13)$ & Type & Public & & \\
\hline & & Private & 7 & 54 \\
\hline & Nature & New con. & 8 & 61.5 \\
\hline & & RMAA & 5 & 38.5 \\
\hline & Cost (Rials) & $<4$ billion & 1 & 25 \\
\hline & & 4-40 billion & 8 & 55 \\
\hline & & $>40$ billion & 4 & 20 \\
\hline & Duration & $<6$ months & 1 & 25 \\
\hline & & 6-14 months & 8 & 55 \\
\hline & & $>14$ months & 4 & 20 \\
\hline
\end{tabular}


Table 6 Status of RM implementation: company level

\begin{tabular}{|c|c|c|c|c|c|}
\hline \multirow[t]{2}{*}{ RMII } & \multicolumn{3}{|l|}{ Grade } & \multirow[t]{2}{*}{ No. } & \multirow[t]{2}{*}{$\%$} \\
\hline & 3 & 4 & 5 & & \\
\hline $0 \%$ & 0 & 0 & 0 & 0 & 0 \\
\hline 1-9\% & 0 & 0 & 0 & 0 & 0 \\
\hline 10-19\% & 0 & 0 & 0 & 0 & 0 \\
\hline 20-29\% & 0 & $1(25 \%)$ & $1(25 \%)$ & 2 & $40 \%$ \\
\hline $30-39 \%$ & 0 & 2 (33.3\%) & 0 & 2 & $40 \%$ \\
\hline 40-49\% & 0 & 0 & 0 & 0 & 0 \\
\hline $50-59 \%$ & $1(50 \%)$ & 0 & 0 & 1 & $20 \%$ \\
\hline $60-69 \%$ & 0 & 0 & 0 & 0 & 0 \\
\hline 70-79\% & 0 & 0 & 0 & 0 & 0 \\
\hline 80-89\% & 0 & 0 & 0 & 0 & 0 \\
\hline 90-100\% & 0 & 0 & 0 & 0 & 0 \\
\hline Total & 1 & 3 & 1 & 5 & $100 \%$ \\
\hline Average & $50 \%$ & $30.53 \%$ & $25 \%$ & $33.32 \%$ & \\
\hline
\end{tabular}

the end, only $9.1 \%$ of projects with a less than 6 months' time duration have RM, while $57.1 \%$ of projects with 6 to 14 months' time duration have implemented the RM. This matter suggests that project management considers RM in small projects as uneconomical due to disproportion between the project duration and consumed time to implement RM. Unlike the primary prediction, only $26.6 \%$ of projects lasted more than 14 months have been implementing RM. Generally, since less than one third of the considered projects have a systematic RM system, the implementation condition of this system is not convenient.

\section{Barriers to risk management implementation}

So, in the first step, a number of barriers to implementation of RM in small construction projects were identified through library studies on previous researches and introduced to experts. In addition, they were asked to identify the barriers preventing RM from being implemented in the related companies' projects. It should be noted that

Table 7 Status of RM implementation: project level

\begin{tabular}{lllll}
\hline Project characteristics & & No. of projects & No. of projects with RM & \% of projects with RM \\
\hline Type & Public & 19 & 6 & 31.5 \\
\multirow{2}{*}{ Nature } & Private & 21 & 7 & 33.3 \\
& New Con. & 21 & 8 & 38.1 \\
Cost (Rials) & RMAA & 19 & 5 & 26.3 \\
& $<4$ billion & 10 & 1 & 10 \\
& $4-40$ billion & 22 & 8 & 36.4 \\
Duration & $>40$ billion & 8 & 4 & 50 \\
& $<6$ months & 11 & 1 & 9.1 \\
& $6-14$ months & 14 & 8 & 57.1 \\
Total & $>14$ months & 15 & 4 & 26.6 \\
\hline
\end{tabular}


given the insufficient research and studies on the subject, all the identified barrier to RM implementation in small projects were approved by a majority of experts.

After considering the questionnaires and removal and merging of the same items, 10 factors have been identified as most influencing factors on the issue which ultimately were described in Table 8.

After identifying the influencing factors on non-implementation of RM in small construction projects, in the next step, experts were asked to determine the relative importance of these factors through identifying the relative importance of each according to the criteria presented in Table 9. After receiving all the expert' opinions, the questionnaires were analyzed through Expert Choice software. Figure 1 shows the output of this software. As you can see, the inconsistency rate of questionnaires is 0.08 which is acceptable according to the number of experts. Meanwhile, the "lack of potential benefits" has been introduced as the most important factor affecting the non-performance of RM in small construction projects in our country, and subsequently, "not economical" has been addressed as another effective factor in this regard. It should be noted that since the mentioned companies has an inappropriate understanding of RM issue, if they are familiar with the advantages of RM implementation, they will definitely be persuaded to use these two factors in their projects. The "lack of time" has been identified as the third most effective barrier among experts. This result confirms the findings of Table 7 showing that a lower proportion of short-term projects tends to implement RM. Small projects are limited by compressed programs and RM development is tedious and time-consuming and project actors are reluctant to implement RM. Also, the results of this discussion confirm that the time spent on managing small projects is disproportionate with cost and project value. Actually, lack of time is a common barrier to RM implementation.

The "lack of budget" has been introduced as the fourth barrier to RM implementation in small projects; like "not economical," it is related to RM implementation being expensive. These results showed that respondents did not believe that RM implementation in small projects is not expensive and the costs of RM implementation in small projects are disproportionate with project costs. The "lack of knowledge" barrier is ranked fifth, and as mentioned before, choosing the lack of potential benefits as the first barrier to RM implementation in such projects is because those companies have an inappropriate understanding about RM discussion which itself comes from lack of

Table 8 Barriers to RM implementation in in small projects

\begin{tabular}{ll}
\hline No. & Barriers to RM implementation \\
\hline 1 & Competition among SMCs \\
2 & Complexity of analytical tools \\
3 & Lack of potential benefits \\
4 & Lack of budget \\
5 & Lack of government legislation \\
6 & Lack of knowledge \\
7 & Lack of manpower \\
8 & Lack of time \\
9 & Low profit margin \\
10 & Not economical \\
\hline
\end{tabular}


Table 9 Language variables and correspondent number for determining the relative importance

\begin{tabular}{llllll}
\hline $\begin{array}{l}\text { Language } \\
\text { variable }\end{array}$ & $\begin{array}{l}\text { Equal } \\
\text { importance }\end{array}$ & $\begin{array}{l}\text { A little more } \\
\text { important }\end{array}$ & $\begin{array}{l}\text { More } \\
\text { important }\end{array}$ & $\begin{array}{l}\text { Very more } \\
\text { important }\end{array}$ & $\begin{array}{l}\text { Absolute } \\
\text { importance }\end{array}$ \\
\hline $\begin{array}{l}\text { Correspondent } \\
\text { number }\end{array}$ & 1 & 3 & 5 & 7 & 9 \\
\hline
\end{tabular}

knowledge in this field. To make an effective and efficient risk management, it is necessary to have a proper and systematic methodology and, more importantly, knowledge and experience of various types. For example, it requires knowledge of the unforeseen events that may occur during the execution of a project, on the actions that work well or not when one of these events happens, on ways to assess a risk or estimate the likelihood that it will occur, and so on [27].

The "lack of government legislation," "lack of manpower," "low profit margin," "complexity of analytical tools," and "competition among SMCs" have been known as lowimpact barriers among experts.

\section{The impact and importance of RM implementation on important project factors}

Investigating the impact and importance of RM implementation on different factors and aspects of small construction projects was considered in this step. According to studies, the quality, cost, and schedule have been identified as main evaluation criteria in all projects, especially small construction projects, which can be considered as the project performance index. For this reason, the performance of small construction projects was evaluated in this factor.

In this regard, the impact of RM implementation and execution on three parameters of quality, cost, and schedule has been evaluated through designing a questionnaire and experts asked the two following questions about each three factors:

A) Does the RM implementation affect the target factor?

B) If it is effective, how impressive is this?

The 5-point Likert scales has been considered for each question to allow experts respond to research questions with more flexibility. For this purpose, three hypotheses were considered which we discuss in the following:

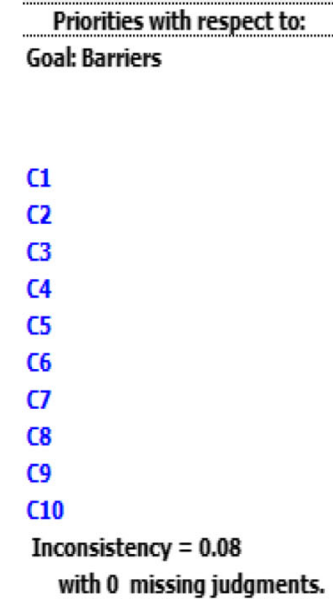

Fig. 1 The output of Expert Choice software 
A) The RM implementation has a positive impact on increasing the quality of small construction projects in Iran

B) The RM implementation has a positive impact on costs reduction of small construction projects in Iran

C) The RM implementation has a positive impact on scheduling improvement of small construction projects in Iran

After questionnaire distribution among the experts and receiving their opinions, first, the validity of questionnaires results was confirmed. Therefore, after the Cronbach's alpha calculation, the number of questionnaires of section 4 was 0.908 . According to this number, the reliability of questionnaires sent to the experts has been approved, so the results of questionnaire analysis are reliable. Table 10 shows the output results of SPSS software, based on the experts' opinions.

According to the results, the significance level of Sig. for all tests is less than 0.05 . Therefore, it can be said that "Research hypotheses about the impact of RM implementation on the important project factors are confirmed." This finding means that RM implementation affects the quality increase, costs reduction, and improving the schedule of small construction projects in Iran.

\section{Conclusions}

In order to investigate the RM situation in small construction projects, the barriers to non-implementation, and its impact on project performance in our country, Iran, this research has been carried out. Generally, given that less than one third of the projects have a systematic RM in total, their implementation terms are not very appropriate more efforts are needed to implement RM in construction projects. If the results are generalized, it can be said that "The RM implementation situation in the country, especially for small construction projects, is not appropriate and desirable."

According to the studies, 10 barriers are identified as major obstacles to RM implementation in such projects, prioritized as follows: (1) lack of potential benefits, (2) not economical, (3) lack of time, (4) lack of budget, (5) lack of knowledge, (6) lack of government legislation, (7) lack of manpower, (8) low profit margin, (9) complexity of analytical tools, and (10) competition among SMCs. Finally, the research hypotheses about the implementation impact of RM on the important project factors were approved. This means that RM implementation affects the quality increase, costs reduction, and improving the scheduling of small construction projects in Iran. In an attempt to investigate the reasons for the low-level RM implementation in Singapore, "lack of time," "lack of budget," "low profit margin," and "not economical" were the prominent barriers that should be overcome by practitioners to appreciate more benefits of RM in small projects [16].

Table 10 The regression test ( $P$ value) of RM implementation impact on projects performance

\begin{tabular}{llll}
\hline Type of impact & $T$ statistic & Standard error & Sig. $(\boldsymbol{P}$ value $)$ \\
\hline $\begin{array}{l}\text { The impact of RM implementation on } \\
\text { project quality improvement }\end{array}$ & 2.701 & 0.127 & 0.0088 \\
$\begin{array}{l}\text { The impact of RM implementation on } \\
\text { reducing project costs }\end{array}$ & 2.684 & 0.135 & 0.0092 \\
$\begin{array}{l}\text { The impact of RM implementation on } \\
\text { improving project scheduling }\end{array}$ & 2.24 & 0.172 & 0.0089 \\
\hline
\end{tabular}


In our country, Iran, the government plays a key role to guarantee the healthy development of construction industry. SMCs are economic entities with limited assets, and they do not have the capacity to allocate additional resources for RM. The small construction projects are critical to the survival of these organizations, such as the development of new products to adapt to the market or new legislation and management system implementations. Very frequently, the managers of these projects are not project management professionals, so they need guidance to have autonomy, using minimal time and documentation resources [19]. In order to encourage SMCs towards RM implementation, it is better for the government to provide financial incentives, such as tax rebates or financial supports; they have a direct impact on profitability and cover the expenses of RM implementation. Therefore, SMCs would not experience the expenses increase, and they will be more tended to run RM.

Subsequently, the government can provide training programs for staff and management in SMCs and then introduce good RM practices which help companies to cope with risks and guarantee the access to function. Employing RM experts in the project and obligation to implement a RM in small construction projects can be named as other strategies.

Although the findings of this study present an understanding of condition, barriers, and impact of RM in small projects of Iran's construction industry, but there are also limitations. First, the necessity of conformity and generalizing the results is completely felt due to the small size of the samples. Also, according to the lack of consensus about small projects definition, this research identifies the range of small projects through two characteristics, costs, and timing of the project. Therefore, the small projects considered in this research may be incomplete. Eventually, the barriers effect on RM, RM importance, and RM impact on project performance were evaluated given the respondents who responded based on their understanding and experience. Therefore, data contains mentality unavoidably. In fact, this is a common problem for researches that use a questionnaire to collect information, and most of the RM evaluations have been based on experience and mental judgment.

Each study can pave the way for more robust and comprehensive researches. This research was no exception and could be a source of better and stronger researches.

According to the results, the following topics can provide a future studies ground for those interested:

- Research can be conducted in other companies (larger statistical community)

- Impact of other factors on time, cost, and quality of the project

- RM effect on the function of large civil projects

- Using other approaches and techniques to analyze the issue

\section{Abbreviations}

RM: Risk management; GNP: Gross national product; HSD: Health and safety directorate; Cll: Construction industry institute; USD: United states dollar; \$: Dollar; SMCS: Small and medium construction companies; SPSS: Statistical

Package for the Social Sciences; y: Year; RMAA: Risk management and audit assurance

Acknowledgements

Not applicable

Authors' contributions

NA performed the conceptualization of the research idea, participated in the interpretation of the results, reviewed the edited manuscript, and supervised the whole project. Also, he contributed to the discussion of the results and visualization of the final manuscript. KS carried out the research methodology, developed the computational 
technique, performed the investigation and validation of the analytical work, and wrote the manuscript draft. The authors read and approved the final manuscript.

\section{Funding}

No specific funding has to be declared for this work.

\section{Availability of data and materials}

The datasets used and/or analyzed during the current paper are available from the corresponding author on reasonable request.

\section{Declarations}

\section{Ethics approval and consent to participate}

Not applicable

\section{Consent for publication}

Not applicable

\section{Competing interests}

The authors declare that they have no competing interests.

\section{Received: 9 August 2021 Accepted: 17 November 2021}

Published online: 16 January 2022

\section{References}

1. Albert A, Hallowell MR (2013) Safety risk management for electrical transmission and distribution line construction. Safety science 51(1):118-126. https://doi.org/10.1016/j.ssci.2012.06.011

2. Ali R (2000) The application of risk management in infrastructure construction projects. Nanyang Technological University, Singapore, M.Sc Thesis

3. Boothroyd C, Emmett J (1996) Risk management: a practical guide for construction professionals. Witherby, London

4. Choudhry RM, Iqbal K (2013) Identification of risk management system in construction industry in Pakistan. Journal of Management in Engineering 29(1):42-49. https://doi.org/10.1061/(ASCE)ME.1943-5479.0000122

5. Chileshe, N., Kikwasi, GJ., (2013), Perception of barriers to implementing risk assessment and management practices by construction professionals in Tanzania, Smith, S.D and Ahiaga-Dagbui, D.D (Eds) Procs 29th Annual ARCOM Conference, 2-4 September 2013, Reading, UK, Association of Researchers in Construction Management, 1137-1146.

6. Chileshe N, Yirenki-Fianko ABE (2012) An evaluation of risk factors impacting construction projects in Ghana. Journal of Engineering Design and Technology 10(3):306-329. https://doi.org/10.1108/17260531211274693

7. CII (2001) Small Projects Toolkit. Construction Industry Institute, Austin, TX

8. Collins W, Parrish K, Gibson G (2017) Defining and understanding "small projects" in the industrial construction sector. Procedia Engineering 196(2107):315-322. https://doi.org/10.1016/j.proeng.2017.07.205

9. Dunston PS, Reed AG (2000) Benefits of small projects team initiative. Journal of Construction Engineering Management 126(1):22-28. https://doi.org/10.1061/(ASCE)0733-9364(2000)126:1(22)

10. Ebrahimiyan H, Fallah AA, Faezi SF (2015) Investigating the factors influencing the risks of small construction projects and their ranking, The First Scientific Congress of the New Horizons in Civil Engineering, Architecture, Culture and Urban Management of Iran. Association for the Promotion of Basic Sciences and Technology, Tehran

11. Fang $\mathrm{CH}$, Marle F (2012) A simulation-based risk network model for decision support in project risk management. Decision Support Systems 52(3):635-644. https://doi.org/10.1016/j.dss.2011.10.021

12. Flanagan R, Norman G (1993) Risk management and construction. Blackwell, Oxford

13. Griffith A, Headley J (1998) Management of small buildingworks. Construct Manage Econ 16(6):703-709. https://doi. org/10.1080/014461998371999

14. Hamdvand M, Eghbali H, Kobraieh Abkenar S, Moghamipour F (2016) Risk assessment in the construction industry of the country. In: International Conference on Civil Engineering. Permanent Secretariat of the Conference, Tehran

15. Ho SSM, Pike RH (2013) Adoption of probabilistic risk analysis in capital budgeting and corporate investment. J Bus Finance Account 19(3):387-405. https://doi.org/10.1111/j.1468-5957.1992.tb00631.x

16. Hwang BG, Zhao X, Toh LP (2014) Risk management in small construction projects in Singapore: status, barriers and impact. International Journal of Project Management 32(1):116-124. https://doi.org/10.1016/j.jproman.2013.01.007

17. Klemetti A (2006) Risk management in construction project networks. Helsinki University of Technology, Helsinki

18. Liang, L., (2005), Small project benchmarking, Ph.D Thesis, The University of Texas at Austin, Austin, TX.

19. Marcelino-Sádaba S, Pérez-Ezcurdia A, Echeverría Lazcano, A. M, Villanueva P (2014) Project risk management methodology for small firms. Int J Proj Manage 32(2):327-340. https://doi.org/10.1016/j.jproman.2013.05.009

20. Mills A (2001) A systematic approach to risk management for construction. Struct Surv 19(5):245-252. https://doi.org/1 $0.1108 / 02630800110412615$

21. Mubarak S (2010) Construction project scheduling and control. John Wiley \& Sons, New York, NY. https://doi.org/10.1 002/9780470912171

22. Nazari A, Forsat kar E, Kia far B (2009) Risk management in projects, President Deputy Strategic Planning and. Control Pub, Co., Tehran

23. PMI (2008) A guide to the project management body of knowledge. Project Management Institute, Newtown Square, PA

24. Ravansar A, Mirzaei R (2016a) The effect of technical and executive factors on risk management of small construction projects in Iran, New Research Conference on Science and Engineering. Qazvin, Allameh Rafiei Institute of Higher Education 
25. Ravansar A, Mirzaei R (2016b) The impact of economic and financial risks on risk management of small construction projects in Iran, New Research Conference on Science and Engineering. Qazvin, Allameh Rafiei Institute of Higher Education

26. Smith GR, Bohn CM (1999) Small to medium contractor contingency and assumption of risk. J Construct Engineer Manage 125(2):101-109. https://doi.org/10.1061/(ASCE)0733-9364(1999)125:2(101)

27. Serpella AF, Ferrada X, Howard R, Rubio L (2014) Risk management in construction projects: a knowledge-based approach. Procedia - Social and Behavioral Sciences 119(2014):653-662. https://doi.org/10.1016/j.sbspro.2014.03.073

\section{Publisher's Note}

Springer Nature remains neutral with regard to jurisdictional claims in published maps and institutional affiliations.

Submit your manuscript to a SpringerOpen ${ }^{\odot}$ journal and benefit from:

- Convenient online submission

- Rigorous peer review

- Open access: articles freely available online

- High visibility within the field

- Retaining the copyright to your article

Submit your next manuscript at $\boldsymbol{\nabla}$ springeropen.com 